Artículo de reflexión

Cómo citar: Jojoa, C. (2020). Cyborgs y fotografía como una extensión de nuestro ser. En: Mediaciones, 25 (16). Pp. 304-316. https://doi.org/10.26620/uniminuto. mediaciones.16.25.2020.304-316

Editorial: Corporación Universitaria Minuto de Dios - UNIMINUTO

Recibido: 31 de agosto de 2020 Aceptado: 20 de septiembre de 2020 Publicado: 16 de diciembre de 2020

ISSN: 1692-5688 | eISSN: 2590-8057

Cindy Estefania Jojoa Ramirez

cjojoaramirauniminuto.edu.co

Estudiante de Comunicación SocialPeriodismo, Corporación Universitaria Minuto de Dios - UNIMINUTO.

\section{Cyborgs y fotografía como una extensión de nuestro ser}

\section{Cyborgs and photography as an extension of our being}

\section{Cyborgs e a fotografia como extensão do nosso ser}

\section{Resumen}

Esta investigación analiza el cyborg como extensión del cuerpo humano a través de la fotografía como medio de comunicación e interacción. Así mismo, se circunscribe a la línea temática de la Escuela de Toronto donde la falta de interpretación de la ecología comunicativa, permite que la focalización teórica constituya la comprensión del postulado de Marshall McLuhan (1964), el cual se centra en la influencia del medio a través del mensaje. En ese sentido, el acto fotográfico de Philippe Dubois (1994) consiste en hallar cómo la fotografía reside en el medio irreductible del acto de su creación, desde una metodología cualitativa con un alcance descriptivo tiene como objetivo exponer los hechos tal como son observados, para establecer el porqué de los mismos. Finalmente, la investigación aporta una percepción visual, el cual evidencia un vínculo entre las extensiones del cuerpo ante el concepto de cyborg y la fotografía, como medio de comunicación.

Palabras claves: cyborg y fotografía, acto fotográfico, ecología de los medios, extensiones del ser humano, humanismo digital.

\begin{abstract}
This research analyzes the cyborg as an extension of the human body through photography as a means of communication and interaction. Likewise, it is limited to the thematic line of the Toronto School where the lack of interpretation of communicative ecology allows theoretical focus to constitute the understanding of the postulate of Marshall McLuhan (1964), which focuses on the influence of the environment. through the message. In this sense, the photographic act of Philippe Dubois (1994) consists of finding how photography resides in the irreducible medium of the act of its creation, from a qualitative methodology with a descriptive scope, its objective is to expose the facts as they are observed, to establish the reason for them. Finally, the research contributes a visual perception, which shows a link between the extensions of the body in the face of the concept of cyborg and photography, as a means of communication.
\end{abstract}

Keywords: cyborg, photography, photographic act, media ecology, extensions of the human being, digital humanism. 


\section{Resumo}

Esta pesquisa analisa o ciborgue como extensão do corpo humano por meio da fotografia como meio de comunicação e interação. Da mesma forma, limita-se à linha temática da Escola de Toronto onde a falta de

interpretação da ecologia comunicativa permite que o enfoque teórico constitua a compreensão do postulado de Marshall McLuhan (1964), que enfoca a influência do meio ambiente. através da mensagem. Nesse sentido, o ato fotográfico de Philippe Dubois (1994) consiste em descobrir como a fotografia reside no meio irredutível do ato de sua criação, a partir de uma metodologia qualitativa de âmbito descritivo, cujo objetivo é expor os fatos tal como são observados, para estabelecer a razão para eles. Por fim, a pesquisa contribui com uma percepção visual, que mostra uma ligação entre as extensões do corpo diante do conceito de ciborgue e a fotografia, como meio de comunicação.

Palavras-chave: ciborgue, fotografia, ato fotográfico, ecologia da mídia, extensões do ser humano, humanismo digital.

\section{Introducción}

El concepto de cyborg protagoniza una serie de distopías tecnológicas en la actualidad debido a que se logra proyectar una percepción diferente del individuo al asimilar que las máquinas o artefactos tecnológicos, como la cámara fotográfica registran una reinterpretación del cyborg, por ello, la investigación se contempla desde un componente social ya que, la ecología de la comunicación dispone de varios recursos tecnológico-digitales apropiados para la recolección y tratamiento de la información en diferentes entornos.

El componente académico evidencia como desde la postura de Giraldo y Maya (2016), la ecología de los medios propone la noción que los modos de información y los códigos de comunicación, ejercen una función transcendental en las interacciones a través de la tecnología, considerando que se relaciona con la Escuela de Toronto y la premisa del "medio es el mensaje”, el pensamiento más conocido de McLuhan, lo cual configura un componente institucional donde se visibiliza los medios de comunicación como extensiones del ser humano y la comprensión del cyborg en términos comunicativos.

No obstante, la problemática que representa la falta de interpretación de la ecología de medios desde su descripción en un contexto determinado, el cual se enmarca en el efecto de aquellas acciones cotidianas que conllevan al uso de las extensiones tecnológicas en el ser humano y la ausencia del análisis crítico de la fotografía como herramienta visual y de reflexión social, surge un interrogante para identificar ¿Cómo el concepto de cyborg y la fotografía se convierten en extensiones del cuerpo humano desde el postulado de Marshall McLuhan?, puesto que es imprescindible reconocer el cyborg a través de la fotografía como extensión y medio de comunicación que implica un proceso de indagación caracterizado por la observación detallada, comprehensiva, sistemática y en profundidad del caso mencionado.

Por tanto, desde un enfoque cualitativo con un diseño hermenéutico y un alcance de tipo descriptivo, se recurre a la estrategia de observar la fotografía y el cyborg como extensión del ser humano, el cual supone una profunda reflexión sobre los procesos de aprendizaje y reconocimiento de la ecología comunicativa desde una perspectiva semiótica, comunicativa 
y el análisis de la práctica fotográfica contemporánea en movimiento con las nuevas modalidades de temporalización de imágenes surgidas a partir del video y de las tecnologías digitales donde se presenta una conceptualización teórica e interpretativa a partir del concepto de cyborg.

De este modo, se genera una serie de fotografías con movimiento como resultado e instrumento social efectivo porque se interpreta al cyborg en términos comunicativos con el objetivo de generar un análisis de relevancia, un impacto socio semiótico y la pertinencia del postulado de McLuhan, el cual evidencia la ampliación de las extensiones del ser humano. En síntesis, la investigación genera un análisis introspectivo de una producción visual que registra el cyborg y la fotografía como extensión del ser en cada imagen para comprender el vínculo entre lo estático y lo móvil, el cual configura un uso comunicativo desde la imagen proporcionado por la tecnología digital.

\section{La importancia de la relación del cuerpo y la imagen en la comunicación}

La relevancia del estudio sobre el cyborg y la fotografía como extensiones del cuerpo humano desde el postulado de Marshall McLuhan, se centra en la transformación de la tecnología y la influencia del medio a través de la ecología de los medios, el cual permite comprender los efectos sociales de las extensiones tecnológicas a partir de la interpretación del concepto de cyborg como imagen y contenido de información desde la escuela de comunicación de Toronto.

Es decir, coexiste una relación conceptual entre la ecología comunicativa y la fotografía porque se destaca el modo en que los medios construyen la realidad del sujeto y del uso de la tecnología, considerando que, la finalidad principal de la investigación se realiza desde esta perspectiva y el estudio de la interpretación del concepto de cyborg. En ese sentido, la fotografía como instrumento de investigación concedido de funciones comunicativas, como: representar e informar desde la observación del entorno, brinda la posibilidad de establecer un análisis que logre incidir en la percepción, reflexión o incluso en la transformación social. En ese sentido, Bonetto (2016) señala que "este consumo masivo de la imagen inherente a las sociedades modernas, se debe a las funciones que tiene la fotografía, a saber: informar, representar, sorprender y hacer significar” (p. 73).

Por ende, la problemática que constituye la falta de interpretación de la ecología comunicativa desde la descripción objetiva de un entorno tecno-humano, se enmarca en el efecto de aquellas acciones cotidianas que conllevan al uso de las extensiones tecnológicas en el ser humano y la ausencia del análisis crítico de la fotografía como herramienta visual y de reflexión social, donde surge un interrogante para identificar ¿Cómo el concepto de cyborg y la fotografía se convierten en extensiones del cuerpo humano desde el postulado de Marshall McLuhan?, considerando que la noción de cyborg permite interpretar las extensiones del cuerpo desde las posibilidades que ofrece la tecnología en el marco de una nueva ontología. 
La relevancia social del estudio sobre el cyborg y la fotografía como extensiones del cuerpo humano, se centra en el componente académico porque evidencia cómo este tipo de extensiones tecnológicas generan una reinterpretación de la realidad de las humanidades digitales, expuesta por la fotografía y su grado de influencia en los receptores, considerando que se relaciona con la escuela de Toronto al concebir que desde la ecología de la comunicación se comprenden los efectos de una sociedad mediada.

De este modo, McLuhan (1964) establece que "las transformaciones de las tecnologías tienen un carácter de evolución orgánica, ya que todas ellas son extensiones de nuestro ser físico" (p. 194) cuya función es interpretada como la experiencia de un proceso de comunicación que es inseparable al ser humano al mantener un contacto interactivo con los demás en un entorno social determinado.

Así mismo, se contempla el concepto de cyborg mediante la premisa de Donna Haraway (1991), donde se comprende al cyborg como un texto, máquina, cuerpo y metáfora, teorizados en la práctica artística y en términos de comunicaciones, puesto que el análisis del acto fotográfico desde el postulado de Philippe Dubois (1994) se obtiene una conceptualización teórica que involucra una acción de difusión del mensaje final que se transmite en la fotografía.

Por ello, se incentiva a la interpretación de las fotografías donde se ejercita la observación detallada con el fin de reivindicar y dotar de sentido el acto fotográfico, como una herramienta de reflexión social del contexto socio semiótico desde la interpretación del concepto cyborg. De este modo, no sólo es un constructo de la era de la información; sino también, es una transformación de un cuerpo marcado por las hibridaciones que se convierten en un agente destinado a un subvertir de las nuevas tecnologías y sus avances en un espacio privilegiado para la cognición socialmente distribuida, puesto que, el individuo está constantemente en un sistema de interacción entre varios sujetos y artefactos tecnológicos. Lo cual permitirá, analizar el cyborg como extensión del cuerpo humano a través de la fotografía como medio de comunicación e interacción.

\section{Semiologia de la fotografía y la ecología comunicativa mediante el cyborg}

\section{Ecología de los medios a través de la fotografía}

Actualmente la fotografía influye en un ambiente mediático y tecnológico debido a que capta la atención visual y el interés del individuo por la escena o composición que se presenta en la imagen, concretamente en su contenido, estructura e impacto. De este modo, la ecología comunicativa es "el estudio de los medios de comunicación en cuanto los entornos" (Postman,1970, como se citó en Scolari, 2015, p. 1030), ya que a partir de la fotografía se halla un ambiente de interacción dinámico con mensajes que inducen a una forma de pensamiento o emoción, según la interpretación del individuo. 
De hecho, la ecología de los medios a través de la fotografía explora la transformación tecnológica en el tiempo, es decir, actualmente los espacios de interacción e intercambio para generar contenido informativo, han proporcionado un ambiente favorable para la emersión de nuevas formas comunicativas, efectos visuales y estéticos, lo cual refleja que la fotografía se adapta a las necesidades del individuo.

Tal es el caso, de la evolución de la fotografía estática a un efecto de movimiento por parte del sujeto que la contempla. Este efecto, se produce mediante aplicaciones tecnológicas, permitiendo que algunos elementos fotografiados tengan ligeras variaciones de movimiento. Este tipo de producciones visuales generan un mayor atractivo hacia el contenido y composición de la imagen, como refiere Cartier (2003) "dentro del movimiento hay un momento en el cual los elementos que se mueven logran un equilibrio. La fotografía debe capturar este momento y conservar estático su equilibrio” (p. 229).

Por tanto, al registrar un acontecimiento o individuo mediante la fotografía, se logra una comprensión de la ecología comunicativa al explorar como se transforma constantemente los medios, no obstante, la fotografía no es solo un producto visual, sino también un medio que esta concedido de una libertad estructural para crear un mensaje, donde Barthes (1982) refiere que "el mensaje fotográfico es un mensaje continuo" (p.13), cuyo significado estético o ideológico, remite a una connotación del receptor que recibe la información, considerando que, la evolución de la fotografía dentro del marco de la ecología comunicativa ha surgido como resultado de la irrupción de nuevas aplicaciones que facilitan métodos de expresión y comunicación para emitir un mensaje.

De esta forma, Barthes (1982) aduce que la fotografía tiene un mensaje connotado, "que es la manera como la sociedad hace leer, en cierta medida, lo que piensa" (p.13), lo cual se evidencia en aquellas ideologías que desean plasmar los sujetos cuando hacen parte de los registros fotográficos o cuando el fotógrafo se interesa por capturar un instante que define un sistema de interacción social. En sí, el mensaje fotográfico contiene una expresión y significado que infiere en el receptor para obtener una interpretación que implica una comprensión de la ecología de medios, considerando que todo entorno tecnológico, expande un sinfín de posibilidades y no impone ciertas limitaciones cuando se desea crear una fotografía, debido a que, los actuales dispositivos fotográficos brindan un fácil acceso para producir contenidos visuales.

\section{El concepto de cyborg y la fotografía como extensiones del ser humano}

La fotografía amplía la noción del comunicador para captar un hecho o experiencia, a través de la cámara como una herramienta tecnológica que puede intervenir simbólicamente en el cuerpo del ser humano, en ese sentido, Haraway (1991) refiere que "las políticas cyborg no consisten entonces ni más ni menos que en luchar por crear lenguajes, imágenes y métodos conceptuales que pueden intervenir en la construcción de los términos del discurso" (p. 47), un acto que se logra desde la fotografía al mostrar la realidad decodificada en un mensaje, donde el receptor transfigura los signos de la imagen en las ideas que desea transmitir el fotógrafo. 
Por tanto, la fotografía está conformada por técnica y tecnología, considerando que al adaptarse a los cambios de la sociedad actual, se inicia una selección de contenido innovador que posee un significado, pero al yuxtaponer una serie de fotografías se estimula nuevas connotaciones en el espectador. Tal como señala Jojoa (2019) “el fotógrafo asume el reto de redimir la esencia creativa de la imagen, ya que está relacionada con el lenguaje simbólico y sus extensiones técnicas de difusión del mensaje” (p. 187), donde la pretensión de invisibilidad de temas cotidianos y expresiones artísticas, se transfiguran en una realidad paralela que se hace perceptible y le confiere interpretaciones inéditas del concepto de cyborg y la fotografía como extensión del ser humano.

Una extensión, que se descubre mediante la función que ejerce el fotógrafo con la cámara para registrar y emplear una técnica, por ello, Haraway (1991) determina que "el cyborg es un constructo heterogéneo y contestado, capaz de apoyar proyectos opositivos y liberadores en los niveles de la práctica investigadora, de las producciones culturales” (p. 365).

Por otro lado, el rol del fotógrafo supone visibilizar las prácticas y el uso de la fotografía en función de registrar la realidad social de un entorno determinado, en efecto, Monje y Ortegon (2016), refieren que "el cyborg de la fotografía es una criatura descentralizada, tiene millones de ojos y una cantidad igual de mentes” (p. 6), es decir, una imagen puede desempeñar diferentes roles en un contexto comunicativo, debido a que capta posiciones individuales que transmiten mensajes e ideologías culturales, para McLuhan (1964), "estos medios, por ser extensiones de nosotros, también dependen de nosotros por sus interacciones y su evolución” (p. 70).

Por consiguiente, la fotografía expresa una antología de manifestaciones individuales e interactivas con el entorno al servicio de los comunicadores sociales que buscan establecer una observación más detallada y sublime de una subjetividad exploratoria de un contexto o individuo. De hecho, McLuhan (1964) señala que "la tecnología de la fotografía es una extensión de nuestro propio ser” (p. 203), ya que la imagen permite que se genere un impacto social ante un registro que revela un mensaje ante el receptor.

Las diversas perspectivas del cyborg tienen una correlación de propósitos en relación con el conocimiento, sustentado en la mediación de tecnologías de la información, según señala Haraway (1991) "el cyborg es texto, máquina, cuerpo y metáfora, todos teorizados e inmersos en la práctica en términos de comunicaciones” (p. 364), lo que ha dado como resultado la diversidad en los procesos de comprensión, contrastación y transferencia de saberes, considerando que "las transformaciones de las tecnologías tienen un carácter de evolución orgánica, ya que todas ellas son extensiones de nuestro ser físico” (McLuhan, 1964, p. 194).

\section{Humanismo digital y el acto fotográfico}

La fotografía desde el humanismo digital se encarga de registrar el conjunto de conocimientos que van movilizando herramientas y perspectivas propias del campo digital, es decir, la comprensión del ser humano en el ámbito digital que constituye el 
centro y evolución del desarrollo tecnológico de las producciones visuales. Por ende, la necesidad de captar y reproducir hechos o acciones, se basa en crear una fotografía que tenga una transcendencia de causa y efecto en el receptor.

De este modo, las herramientas tecnológicas como las aplicaciones que facilitan los retoques y efectos en las fotografías, proporcionan aspectos técnicos que responden a intenciones creativas por parte del fotógrafo, para impresionar al espectador, creando trucos visuales, los cuales son posibles graciaas a los nuevos avances en la creación digital de la fotografía.

Esta idea significativa, se puede englobar desde una retrospectiva de la mayoría de técnicas actuales que se emplean para hacer fotografías desde un entorno comunicativo, en ese sentido, Ursua (2016) aduce que las humanidades digitales son "una transdisciplina portadora de los métodos, dispositivos y perspectivas heurísticas relacionadas con procesos de digitalización en el campo de las Ciencias Humanas y Sociales” (p. 34), considerando que la relevancia de estos métodos digitales para la creación de efectos visuales, se emplean como recurso para indicar las transiciones comunicativas al transmitir un mensaje o información desde el acto de su creación. De hecho, el acto fotográfico involucra una acción de difusión del mensaje final que se transmite en la imagen para establecer una relación con el tiempo, los signos y los sujetos; "pues la fotografía, [...] no es solo una imagen producida por el acto, es también, ante todo, un verdadero acto icónico "en sí», es consustancialmente una imagen-acto” (Dubois, 1994, p. 54), puesto que, el contenido con una forma no solo reproduce un mensaje, sino que el acto fotográfico se sitúa y actúa porque permite crear una acción irreductible al experimentar con escenas propias y ajenas al fotógrafo.

Un proceso por el cual las imágenes se crean y no se manipulan en un contexto de una sesión en acción, ya que, el acto fotográfico activa múltiples formas de realizar la imagen para producir una admiración por parte del receptor e incluso una práctica social en la construcción de producciones visuales. Por ello, McLuhan (1964), señala que "en una cultura como la nuestra, con una larga tradición de fraccionar y dividir para controlar, puede ser un choque que le recuerden a uno que, operativa y prácticamente, el medio es el mensaje” (p. 29).

La cámara fotográfica no es el mensaje sino es el acto fotográfico que se encarga de crear y difundir el significado de la información contenida en la imagen, debido a que la tecnología permite el desarrollo de la creatividad y la percepción de las fotografías de una forma heurística, considerando que "las tecnologías digitales nos ofrecen hoy gran cantidad de información, donde podemos identificar: Patrones o modelos de todo el espectro de fenómenos que van de lo concreto y material a lo más abstracto usando un mismo leguaje" (Ursua, 2016, p. 35). De hecho, a través del lenguaje audiovisual que se consume en la actualidad, se puede explorar formas interactivas de crear y producir fotografías, tal como refiere Bauman (2005) "la vida líquida dota al mundo exterior y, de hecho, a todo aquello que hay en el mundo" (p. 14), es decir, la fotografía genera una atracción constante por su poder seductivo y el fotógrafo tiene la habilidad de captar su trabajo creativo en el transcurso mismo del acto fotográfico. 


\section{Reflexión hermenéutica de la imagen}

El planteamiento hermenéutico de la investigación consiste en una reflexión sobre la interpretación de la imagen como medio para comprender el cyborg y la fotografía, por ende, el estudio es de tipo cualitativo, analizando la forma en que los individuos participantes, perciben y experimentan desde la fotografía, sus extensiones tecnológicas, la ecología comunicativa y el concepto de cyborg, bajo un diseño de tipo descriptivo mostrando los hechos tal como son observados.

La población seleccionada fueron los habitantes del municipio de Tocancipá (Cundinamarca), debido a que experimentan cambios en el ámbito digital que conllevan a una incorporación de la fotografía en sus acciones cotidianas para informar, percibir las transformaciones de su entorno, crear contenidos y analizar su realidad social, el cual permite identificar el focus group, conformado por mujeres y hombres habitantes del municipio entre los 18 y los 46 años de manera aleatoria.

Empleando una muestra homogénea no probalística aleatoria, debido a que las opciones de la composición de la fotografía y los participantes, no dependen de una probabilidad de ser elegidos, sino de las causas y efectos relacionados con la investigación, donde la población posee un mismo perfil o características equivalentes al uso de la fotografía en su cotidianidad.

\section{Discusión}

La investigación se relaciona con la escuela de comunicación de Toronto, debido a que se ahonda en las formas en que se perciben y se procesa la información a través del postulado el medio es el mensaje, donde McLuhan (1964) señala que "de nuestras extensiones, resultan de la nueva escala que introduce en nuestros asuntos cualquier extensión o tecnología nueva” (p. 29), es decir, en este caso la fotografía es una extensión del ser a través de la cámara, ya que produce contenidos en diversos ambientes para transmitir un mensaje. Por otro lado, Barthes (1982) sostiene que el mensaje fotográfico es "un mensaje continuo" (p. 13), considerando que, la fotografía no es sólo producto, sino que también posee una autonomía estructural de connotación, donde el emisor la emplea de una forma creativa para que el receptor pueda observar la imagen de modo subjetivo con el fin de que el individuo llegue a una conclusión indirectamente.

En ese sentido, "el mensaje connotado comprende efectivamente un plano de la expresión y un plano de contenido, significantes y significados” (Barthes, 1982, p. 16), es decir, la fotografía se descifra con una interpretación que varía de acuerdo al análisis del espectador, debido a que la connotación explica cómo se da un mensaje en el contexto comunicativo mediante la composición de la imagen que hace posible su producción, en efecto, "los medios o extensiones del hombre son «agentes" hacen que algo suceda" (McLuhan, 1964, p. 70). 
Por ello, la fotografía no es solamente percibida, sino que permite una lectura más allá de los límites de representación, en el caso del cyborg algunos receptores lo analizan como un híbrido de tecnología, no obstante, los fotógrafos y comunicadores lo proyectan como una metáfora que permite una construcción visual del cuerpo y sus expresiones artísticas que se constituyen como un medio, como refiere Haraway (1991) "el cyborg es una especie de yo personal, postmoderno y colectivo, desmontado y vuelto a montar" (p. 279), puesto que, el individuo crea sinergias transformadoras en su interior al interactuar con medios tecnológicos:

Una respuesta al mayor poder y velocidad de nuestro cuerpo extendido consiste en generar nuevas extensiones. Toda tecnología crea nuevas presiones y necesidades en los seres humanos que la engendraron. Las nuevas necesidades y respuesta tecnológica nacen de nuestra adopción de tecnologías ya existentes, en un proceso sin fin (McLuhan, 1964, p.194).

Un proceso que se logra mediante la imagen con un trasfondo social que le confiere significados al ser humano ante la necesidad de expresar sus motivos artísticos, simbólicos, su interés de expandir conocimientos, ideologías y mediaciones con su poder adquisitivo de información, ya que el mensaje se transmite por necesidad lógica, emotiva y subjetiva de acuerdo a la intencionalidad del fotógrafo con un intercambio comunicativo, el cual permite que el receptor obtenga una connotación del mensaje sin instrucción alguna, porque es libre de evocar su sensibilidad estética ante la imagen.

\section{Resultados}

A partir de la indagación y la realización de una producción visual con efectos de movimiento en las imágenes, se interpreta la fotografía como extensión del ser humano desde el registro de la realidad mediante las expresiones artísticas y las manifestaciones del cyborg posmoderno, considerando que, la ecología de la comunicación permite comprender como las interacciones de los individuos con los medios actúan como una interfaz de experiencia, sentido y semiótica desde los artefactos tecnológicos que coadyuvan a una creación de contenido con un mensaje connotado, por tanto, McLuhan (1964) refiere que:

Todos los medios son extensiones del cuerpo y de los sentidos puesto que, en la experiencia propia, solemos traducir un sentido en otro, no debería sorprendernos que nuestros sentidos extendidos, o tecnologías, repitan el proceso de traducción y asimilación de una forma en otra (p. 132).

En este caso la fotografía es un medio de información y trabajo artístico que ahonda en un momento íntimo, plasmado y recordado con el objetivo de darle un soporte a su significado, puesto que la aparición de la cámara fotográfica incorporada en los dispositivos móviles, ha generado que el sentido de captar cada hecho o expresión en la vida diaria a través de la fotografía, se convierta en una extensión del ser. Como refiere Bauman (2005) "la sociedad moderna y la vida líquida se hallan atrapadas en una especie 
de móvil perpetuo" (p. 15), es decir, la vida líquida hace referencia a la trasmutación de la sociedad, debido a que la evolución tecnológica permite una forma de interacción, que se consolida en un hábito y rutina determinada que se renueva constantemente al adquirir nueva información, como es el caso del fotógrafo que se encarga de registrar y comunicar una realidad transformada con cierta facilidad mediante la cámara fotográfica, ya que "cada encuentro supone tanto una conclusión como un nuevo inicio: la interacción no tiene un «final natural»" (Bauman, 2005 p.112).

\section{Imagen 1 \\ Algunas de las fotografías empleadas con efecto cinético}
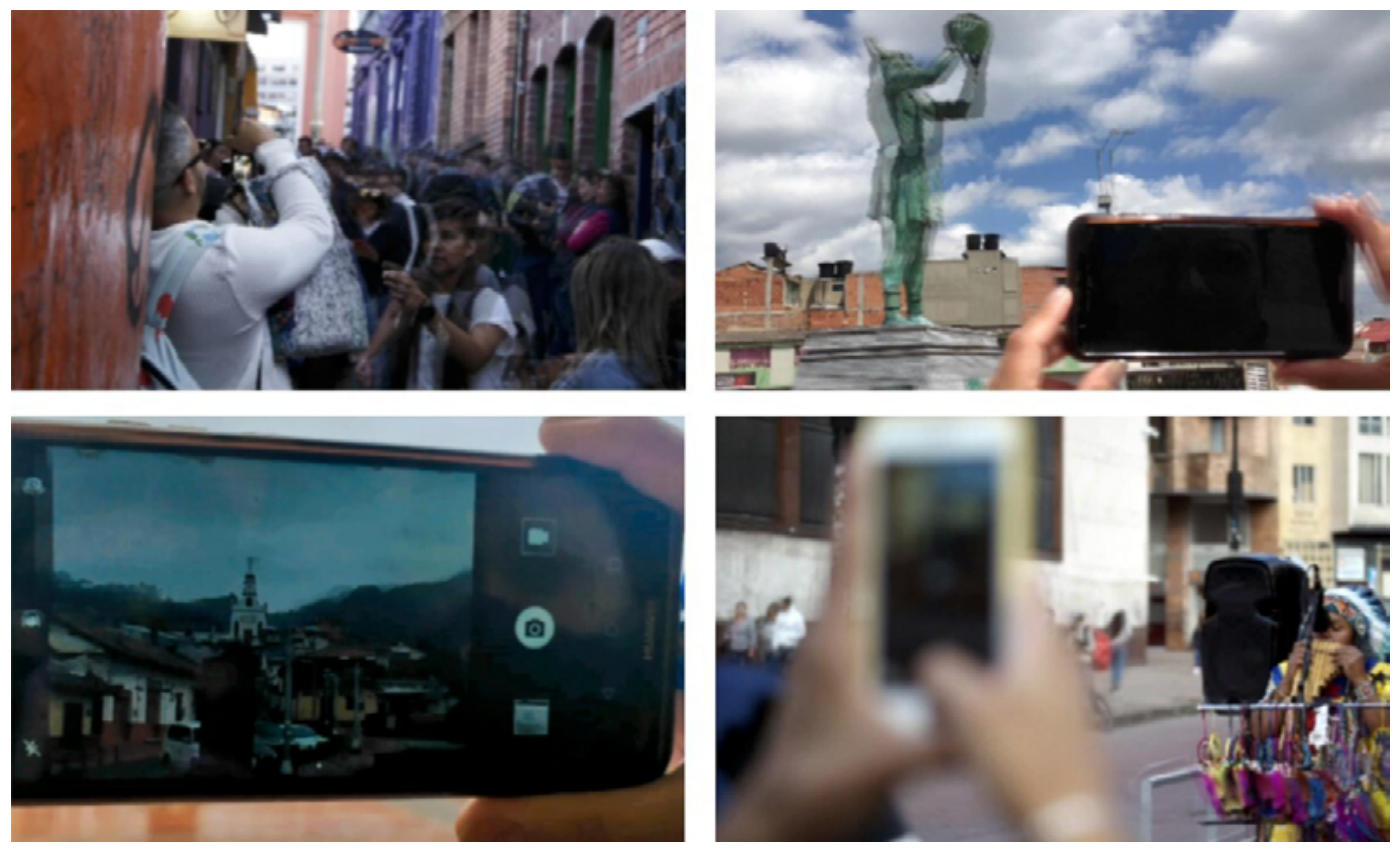

Fuente: Jojoa, 2020

De este modo, el instrumento de medición empleado se da a partir de una encuesta de tipo cualitativa, aplicada a 63 individuos objeto de estudio en la investigación con edades que oscilan entre los 18 a 46 años, donde se detecta que para la mayoría de los encuestados, el concepto de cyborg es interpretado como híbrido de máquina y organismo, este concepto no sólo es un constructo de la era tecnológica; sino también, es una transformación y adaptación del ser humano, ya que el individuo está constantemente en un sistema de interacción entre varios sujetos y artefactos tecnológicos.

Se determina que para los sujetos participantes, las extensiones del ser humano son interpretadas como un medio tecnológico y herramienta que extiende las habilidades humanas, ya que, la fotografía es una extensión que se complementa del humanismo digital como una disciplina portadora de procesos de digitalización en el campo de las 
ciencias humanas y sociales. Por otro lado, se examina que la ecología comunicativa es analizada en la investigación, como el estudio de los modos de información y los códigos de comunicación en los asuntos humanos, debido a que, permite comprender como las interacciones de los individuos con los medios, actúan como una interfaz de experiencia, sentido y semiótica desde los artefactos tecnológicos.

De hecho, varios individuos participantes en la investigación, refieren que el movimiento en las fotografías, es la convergencia de los entornos comunicativos y la experiencia creativa del fotógrafo, ya que se comparte una representación visual con determinados efectos sobre la imagen, con el propósito de generar un impacto ante el receptor sobre el mensaje fotográfico que se está comunicando, según un encuestado: "este tipo de movimiento apoya la exposición de la simple imagen, ambientando y logrando un buen impacto visual en el espectador” (Anónimo, 2020).

En efecto, cada interacción le permite al receptor apreciar la fotografía desde una postura crítica porque la interpreta como una herramienta que registra un momento único en un contexto determinado, donde el individuo tiene la opción de analizar desde una forma inconsciente, el mensaje que contiene la imagen, puesto que, organiza su mirada a través de los elementos más llamativos de la producción visual e infiere unas conclusiones que conllevan a un impacto o reflexion sobre la misma. La fotografía en esta investigación, se transforma en un elemento visible de las extensiones del ser humano desde un trasfondo que se hace perceptible las prácticas artísticas en la actualidad, con elementos que incentivan al receptor a interrogarse acerca del sentido de la composición de la imagen, su elaboración y la significación que se le otorga al observar el contenido.

\section{Conclusiones}

La fotografía como una extensión del ser, es un medio que aumenta la conciencia semiótica y simbólica en el receptor con un uso social, debido a que la ecología de la comunicación constituye en el individuo desde el punto de vista artístico y cultural, aquellas percepciones que se hallan vinculadas a sus procesos de adaptación en las condiciones comunicativas que desarrollan las interacciones entre seres humanos.

Por ende, el cyborg es una metáfora y habitante del mundo postmoderno, Haraway (1991), considerando que, el fotógrafo es capaz de lidiar con los avances tecnológicos para realizar y editar una imagen con su habilidad de percibir la transformación que experimentan los sentidos de los individuos, cuando reaccionan frente a los medios con expresiones artísticas, lo que genera un contenido con significado.

A partir de esta interpretación, se establece el vínculo entre el sujeto-consumidor de su humanismo digital, ya que al reconocer la producción de contenido informativo, el individuo hace parte de la producción visual de sí mismo porque se constituye un hibrido donde tiene acceso a la tecnología e implementa una forma de participación y creación de fotografías, debido a que todos los medios son extensiones del ser, McLuhan, (1964); donde varias partes de nosotros se comprenden en diversos materiales 
Por tanto, la fotografía es una extensión que se complementa del humanismo digital por la hibridación, la convergencia de los entornos comunicativos y la experiencia creativa del fotógrafo que comparte una representación visual artística con determinados efectos sobre la imagen para generar un impacto ante el receptor sobre el mensaje fotográfico que se está comunicando.

De este modo, Bauman (2005) refiere que la hibridación es una declaración de emancipación y de independencia acompañada de soberanía sobre las prácticas, de hecho, los fotógrafos han experimentado estéticamente una hibridez que mezcla lo tecnológico con un lenguaje semiótico que expresa aquellas prácticas artísticas e interpretaciones de la realidad, alternativas de contenido informativo del actual humanismo digital que trata de lograr una equidad e integración con lo diferente.

En síntesis, se detecta que la influencia de las teorías trabajadas en la investigación, se determina ya que la fotografía es también una extensión de nuestro pensamiento al crear una imagen, partiendo de la necesidad de explorar a nivel simbólico todo acto creativo, sobre nuestro proceso mental y emocional en la construcción de nuestras imágenes. En cuanto al cyborg, se convierte en extensión de nuestro ser, porque al identificar desde niños nuestro yo personal, basado en el postulado de Haraway (1991) donde aduce que el cyborg es un yo, postmoderno y colectivo, donde se establece el vínculo entre el sujeto-consumidor de su humanismo digital, considerando que, al reconocer la producción del contenido de la fotografía, el individuo hace parte de esa producción visual de sí mismo, porque se constituye un híbrido donde tiene acceso a la tecnología de la fotografía e implementa una forma de participación y creación de la imagen.

\section{Referencias bibliográficas}

Barthes, R. (1980). La cámara Lucida. Paidós.

Barthes, R. (1982). Lo obvio y lo obtuso. Paidós.

Bauman, Z. (2005). Vida Líquida. Paidós.

Bonetto, M. J. (2016). El uso de la Fotografía en la investigación social. Revista Latinoamericana de Metodología de la Investigación Social: ReLMIS, (11), 71-83. https://dialnet. unirioja.es/servlet/articulo? codigo $=5454287$

Cartier-Bresson, H. (2003). El instante decisivo. En J. Fontcuberta (Coord.). Estética fotográfica: una selección de texto (1ra ed., pp. 221-236). Editorial Gustavo Gili, SA.

Dubois, P. (1994). El acto fotográfico. Paidós 
Giraldo, A., y Maya, C. (2016). Modelos de ecología de la comunicación: análisis del ecosistema comunicativo. Palabra Clave, 19(3), 746-768. https://www.redalyc.org/ pdf/649/64946476004.pdf

Haraway, D. (1991). Ciencia, cyborgs y mujeres. La reinvención de la Naturaleza. Cátedra.

Jojoa, C. (2019). Cyborgs, estética y discurso para alfabetización visual en materia de género desde la fotografía artística en la comunidad LGBTI de Bogotá. En Gómez, A [et. al]. (Coord.). Diseño y Creación (1ra ed., págs. 182-195). Universidad de Caldas.

McLuhan, M. (1964). Comprender los medios de comunicación. Las extensiones del ser humano. Paidos.

Monje, D., y Ortegon, N. (2016). Eugène Atget, el Cyborg de París y su relación doble vincular. ASRI: Arte y sociedad. Revista de investigación, (11), 1-7 https://dialnet.unirioja. es/servlet/articulo?codigo $=5688686$

Scolari, C. (2015). Los ecos de McLuhan: ecología de los medios, semiótica e interfaces. Palabra Clave, 18(4), 1025-1056. https://www.redalyc.org/pdf/649/64942535004.pdf

Ursua, N. (2016). El pensar humanístico frente a las "humanidades digitales”. Límite. Revista Interdisciplinaria de Filosofía y Psicología, 11(36), 32-40. https://www.redalyc. org/pdf/836/83646546003.pdf 